\title{
Predesign of a cylinder head of compression ignition engine
}

The paper presents the initial design of the four-cylinder CI engine head and the analysis of the strength of the head with the use of FEM. The article covers: general assumptions of the designed head, analytical design calculations, three-dimensional head model and timing system components using CAD. The scope of calculations using the head calculation model includes strength calculations and determination of the amount of strain caused by the given load.

Key words: cylinder head, stress analysis, FEM

\section{Preparation of 3D models of being designed cylinder head and components of timing system, elaboration of design documentation and documentation for further development of the cylinder head model}

The 3D model of being designed cylinder head together with its cover (called as cam carrier) was made with use of the Autodesk Inventor Professional program, according to adopted earlier assumptions and performed analytical calculations, having simultaneously in mind effect of ordering of individual components of timing system on geometry of the structure. 3D models of timing system components have been also generated. Possibility of generation of accurate model of being designed structure has been also taken into account during creation of the cylinder head model. Effective development of the cylinder head model was possible owing to the following activities [2-7]:

- adoption of type of the timing system;

- making of assumptions about method of mutual cooperation between components of timing system;

- making selection of material for the cylinder head and components for the timing system;

- making of initial analytical calculations;

- based on performed calculations, modelling of components of the timing system;

- modelling of lower plate of the cylinder head, together with positioning and modelling of holes for valve seats in area of contour of the cylinder and seat of the injector;

- modelling of inlet and outlet channels with geometry assuring correct flow of gases;

- modelling of side walls of the cylinder head and columns, which assure positioning of the screws to connect the cylinder head with the cylinder block;

- modelling of upper plate of the cylinder head (cam carrier), together with valve seats and valve spring;

- modelling of bearing system of camshafts;

- modelling of front and rear walls together with inlet and outlet oil ducts to components operated with friction;

- arrangement and modelling of holes in the cylinder head, enabling attachment with the cam carrier;

- modelling of the cam carrier.

\section{Stress analysis of the cylinder head model with use of the FEM program}

Stress analysis of the cylinder head was performed with use of the ANSYS R17.2 Academic Research program [1, 5].

To perform the analysis, cylinder head model was simplified (Figs 1-4) by plugging valve seats of inlet and outlet channels, and seat of injector. Moreover, components of the timing system were removed from the geometrical model.

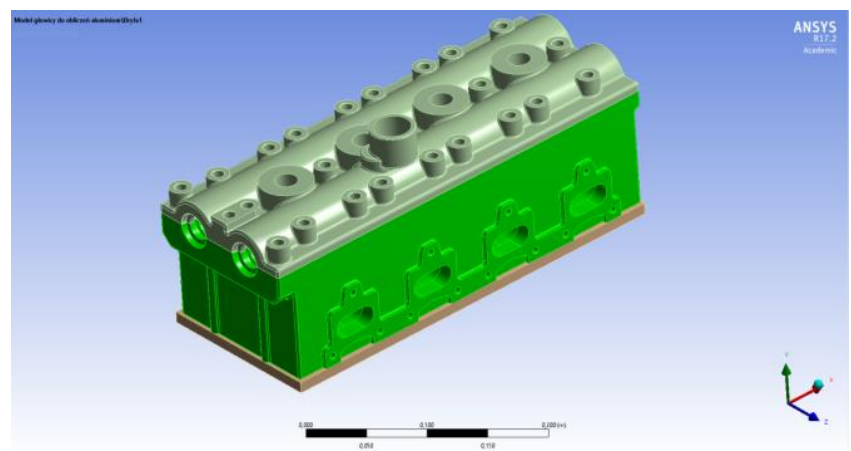

Fig. 1. Geometrical model of the cylinder head - general view

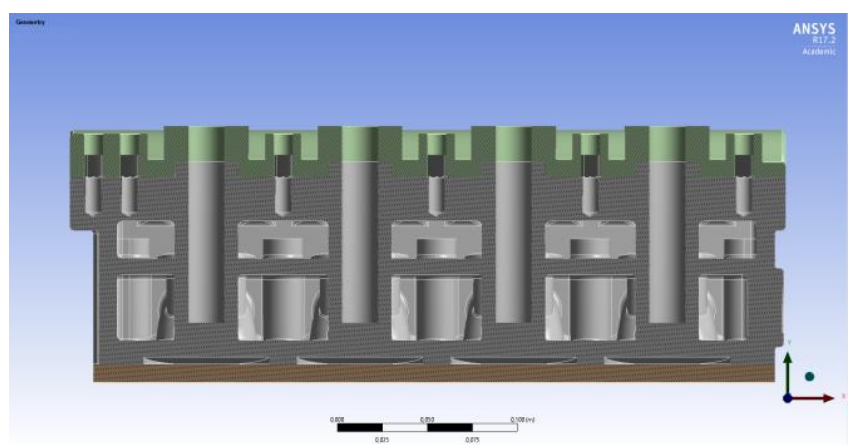

Fig. 2. Geometrical model of the cylinder head - longitudinal section

To approximate simulation to the real conditions, the model also comprises, except the cylinder head, the cam carrier (Fig. 5), which is connected (Fig. 7 and 8) to the cylinder head in locations anticipated in real structure for screw type connections. As the screw connections were not analysed in this study, they have been taken as a stiff ones, thus indicating on fact that they were suitably selected, joining the cylinder head with the cam carrier in a proper way. 


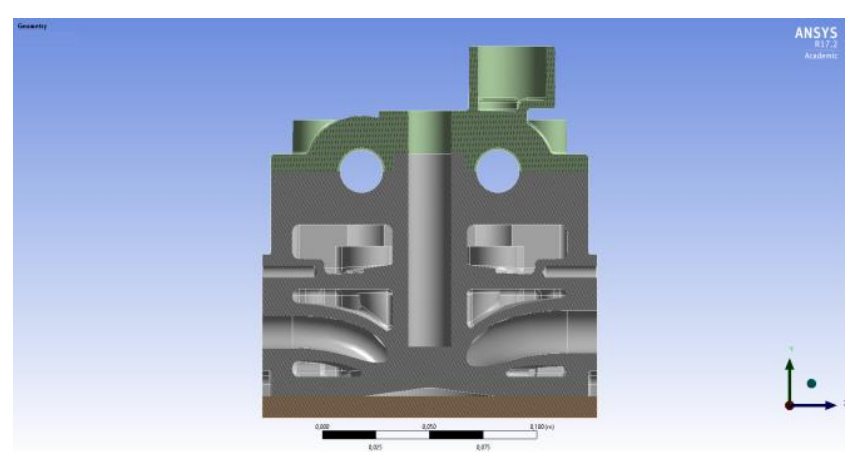

Fig. 3. Geometrical model of the cylinder head - cross section

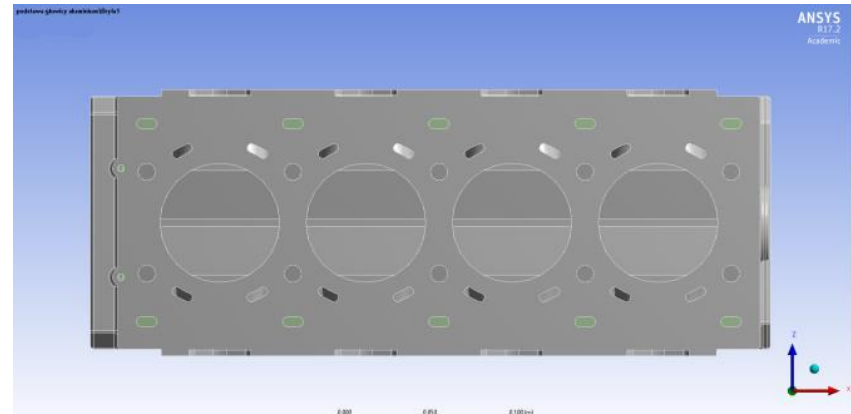

Fig. 4. Geometrical model of the cylinder head - bottom view

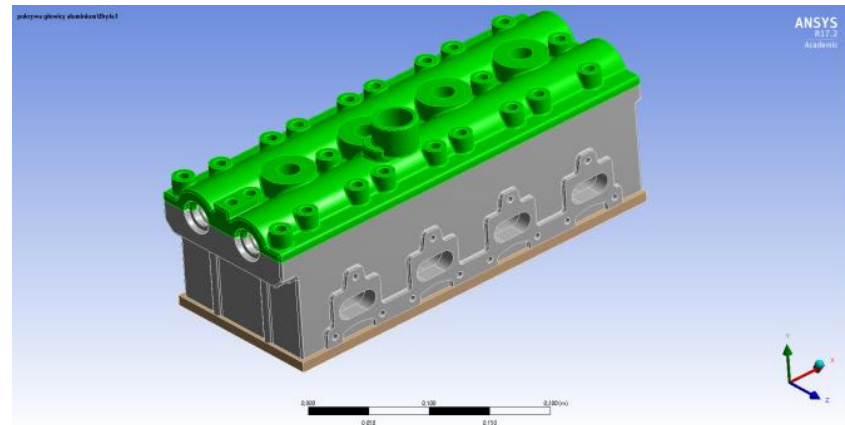

Fig. 5. Geometrical model of the cam carrier - general view

Geometrical model of the cylinder head with the cam carrier was suppressed on the plate (Fig. 6) simulating the cylinder block. Face of the plate being in contact with bottom face of bottom plate of the cylinder head was used as a support of the model. Connection of the cylinder head with the plate (Figs 7 and 8) was implemented in the same way as connection of the cylinder head with the cam carrier.

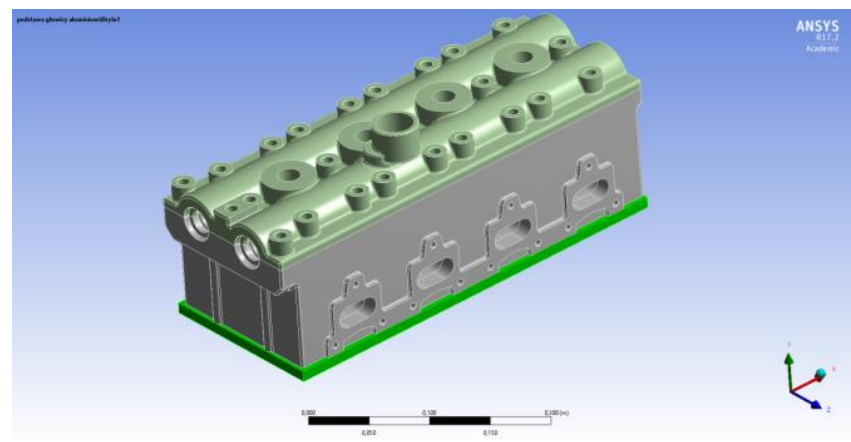

Fig. 6. Geometrical model of the bottom plate of the cylinder headgeneral view

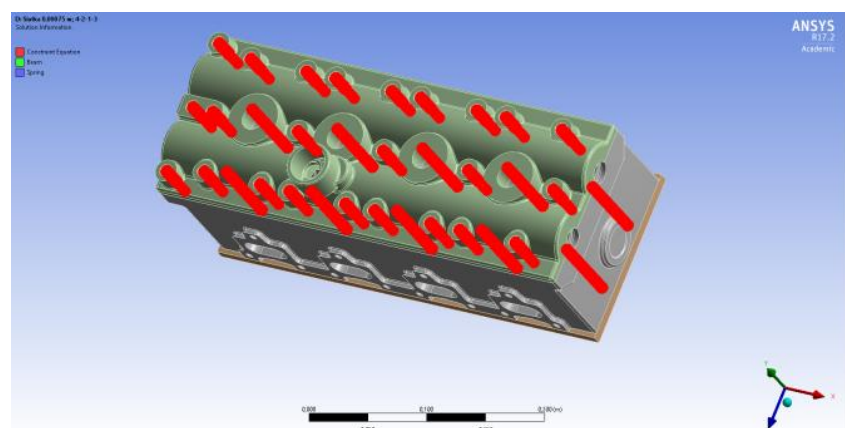

Fig. 7. Connections of the model of cylinder head with the model of cam carrier and connections of the model of cylinder head and the model of bottom plate of the cylinder head - general view

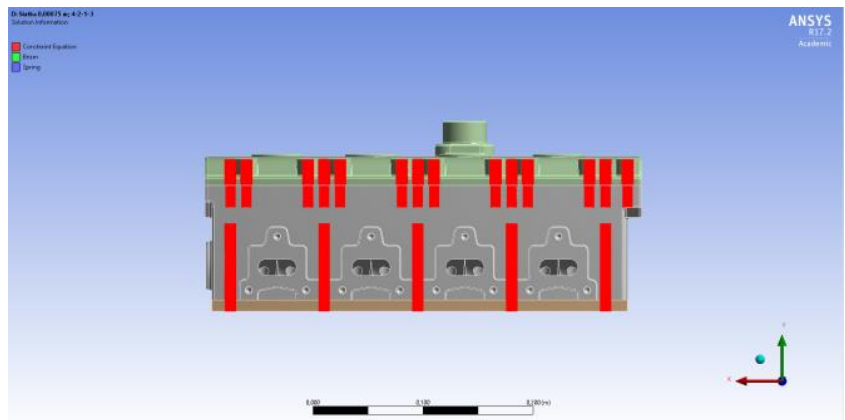

Fig. 8. Connections of the cylinder head model with the model of cam carrier, and connections of the cylinder head model with model of bottom plate of the cylinder head - view from exhaust channels side

Load of the cylinder head was applied through loading of closing surface of working space over the cylinder block of each cylinder bore separately (Fig. 9).

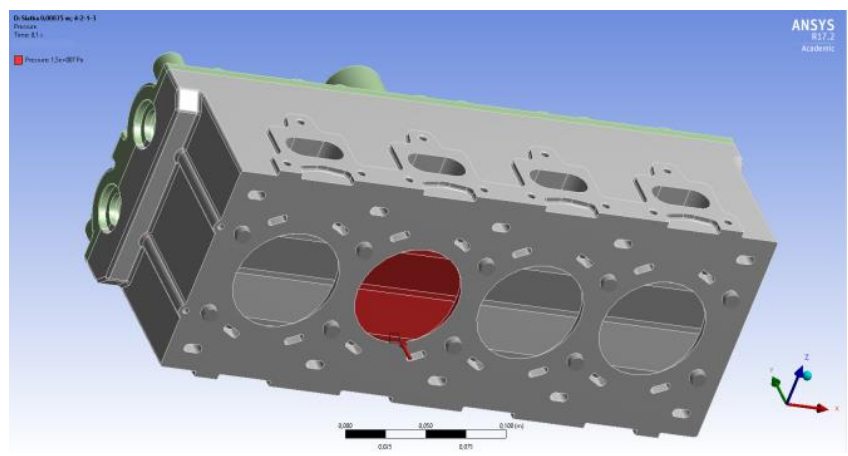

Fig. 9. Method of application of load on example of the 2nd cylinder

Imposed load was equal to maximal pressure in combustion chamber of real compression ignition engine. Readout of its value was made on the base of indicator diagram of this engine, representing pressure course in function of crank angle (Fig. 10), in full load conditions at crankshaft speed of $4000 \mathrm{rpm}$.

Geometrical model of the cylinder head has been discretized. Equivalent to continuous system, discrete system was built from finite elements with four nodes and four walls, having edge size of $0.75 \mathrm{~mm}$ (Fig. 11). Such values result from limited computation power of computer system used to simulation of the model. 


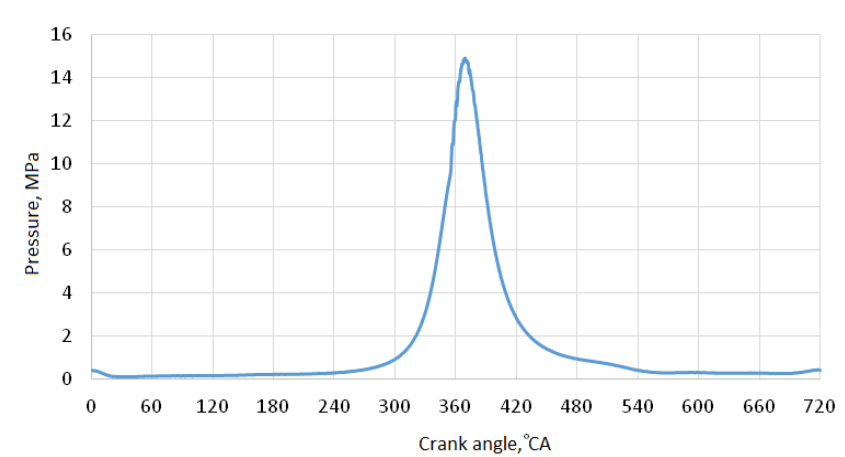

Fig. 10. Cylinder pressure run in function of crank angle of compression ignition engine for full load at $4000 \mathrm{rpm}$

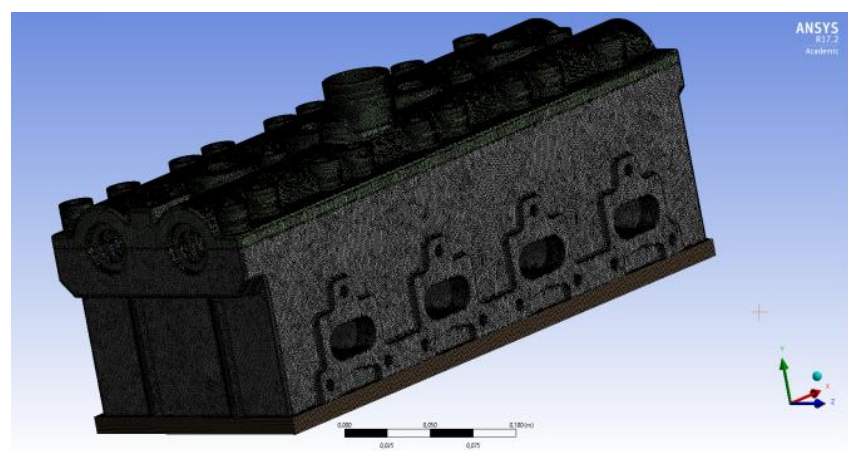

Fig. 11. Discrete geometrical model, size of finite elements equal to 0,75

Calculations time amounted approximately to 30 hours for each, from four analyzed load cases.

\section{Results of the investigations}

In the text below are summarized obtained results of the simulations, performed with of the FEM method, which were accomplished according to the criteria adopted in the present study. Performed simulation has allowed for approximate evaluation of:

- Total deformation;

- Directional deformations in directions concurrent with „x", ,y” and ,z" axes.

\subsection{Simulation results of the first cylinder loading}

a) Total deformations (Figs 12-15):

The highest deformations, included within limits of $0.080-0.086 \mathrm{~mm}$ are seen in area of valve seats, and injector seat, under load of pressure in the cylinder. Area of the

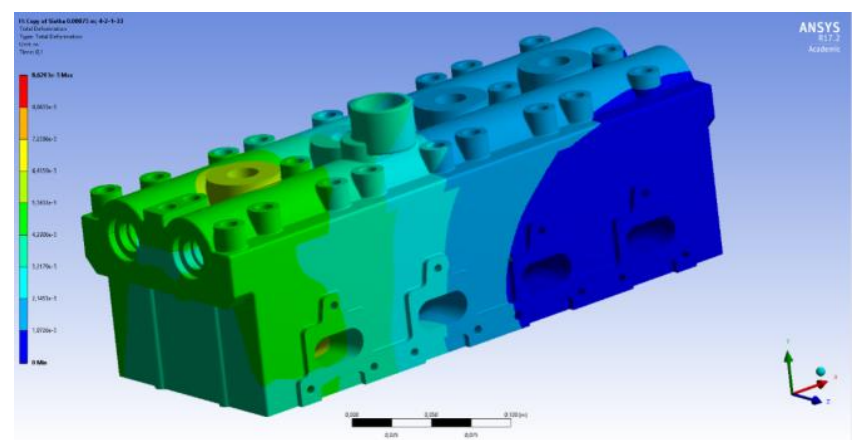

Fig. 12. Distribution of total deformations as result of simulation of the first cylinder loading- general view deformations close to valve seats, from inlet manifold side, is larger than in area close to valve seats from exhaust manifold side.

The smallest deformations are seen in area behind the second cylinder, in direction of the third cylinder, and fall within limits of $0.000-0.010 \mathrm{~mm}$.

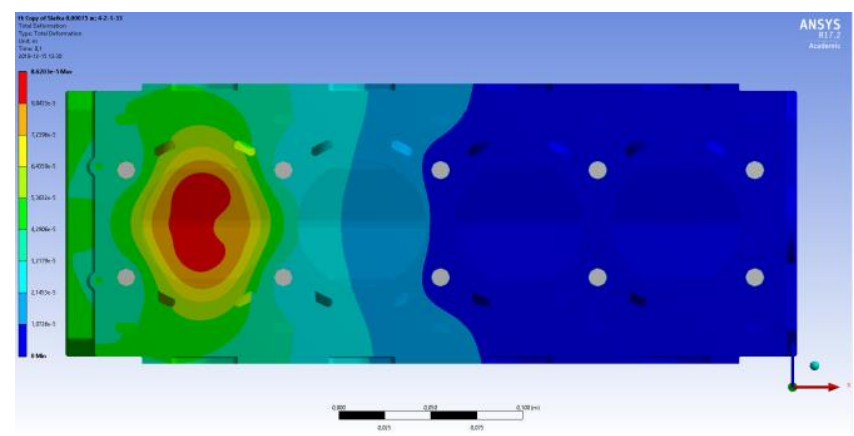

Fig. 13. Distribution of total deformations as result of simulation of the first cylinder loading - bottom view

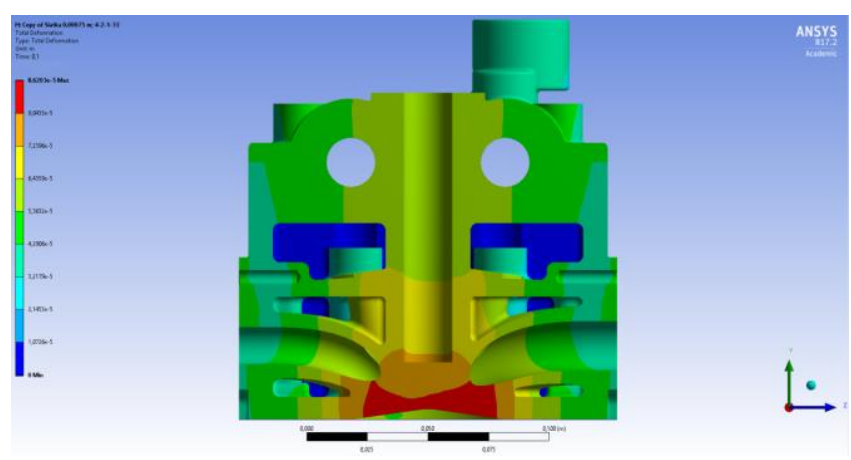

Fig. 14. Distribution of total deformations as result of simulation of the first cylinder loading - cross-section of the first cylinder

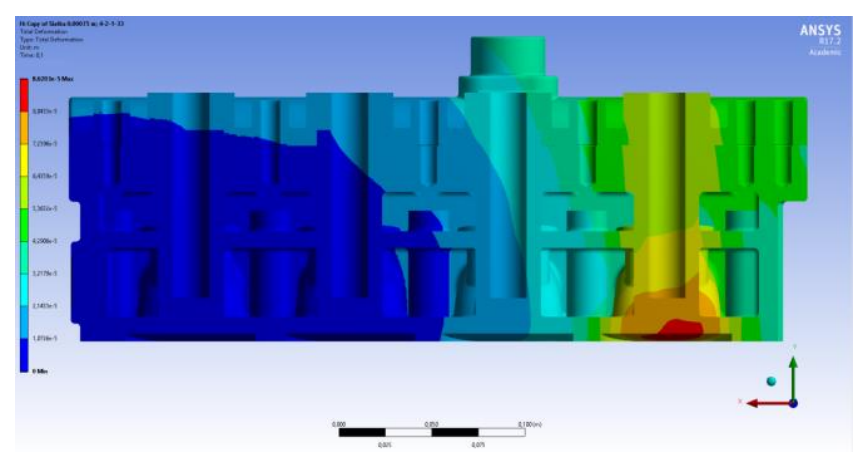

Fig. 15. Distribution of total deformations as result of simulation of the first cylinder loading - longitudinal section

b) Directional deformations concurrent with ,x” axis (Figs 16 and 17):

The highest deformations in direction of „,X” axis, consistent with its sense, are included within limits of $0.019-$ $0.026 \mathrm{~mm}$ and are seen in area of oil filler in the cam carrier.

However, the highest deformations in direction of „x" axis, opposite to its sense, are included within limits of $0.003-0.013 \mathrm{~mm}$, and are seen in bottom plate of the cylinder head, partially in area of loaded cylinder, and in area of the second cylinder. 


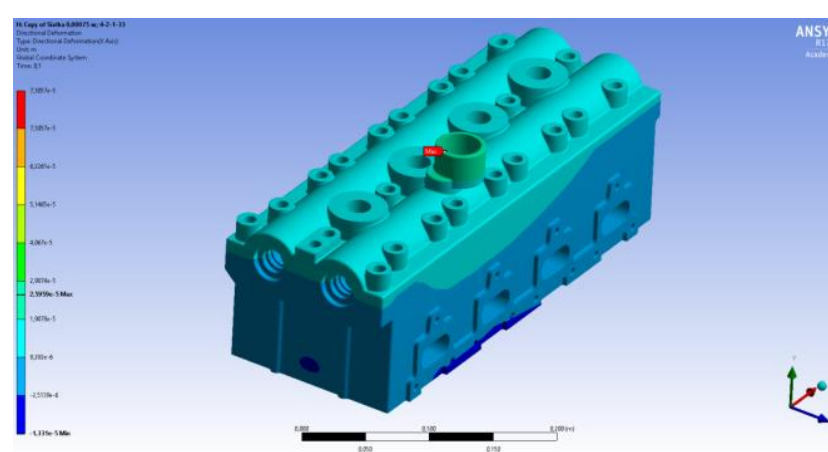

Fig. 16. Distribution of the deformations in direction of „x” axis as results of simulation of the first cylinder loading - general view

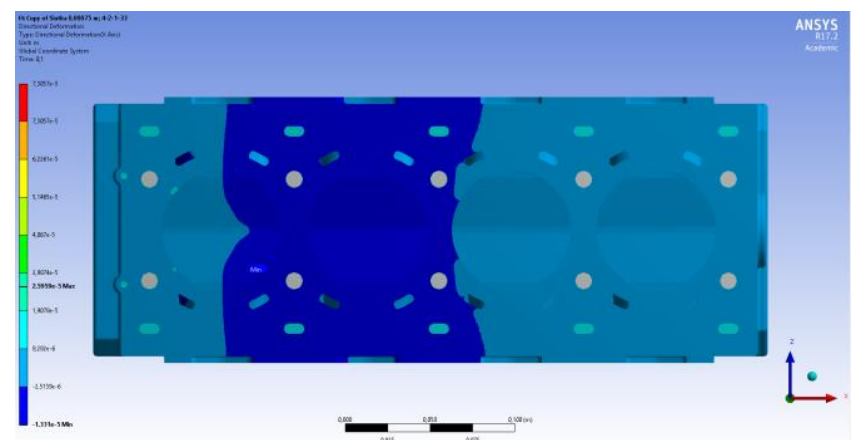

Fig. 17. Distribution of the deformations in direction of ,x” axis as results of simulation of the first cylinder loading - bottom view

c) Directional deformations concurrent with ,y” axis (Figs 18-20):

The highest deformations in direction of ,y” axis, consistent with its sense, are contained within limits of 0.073 $0.086 \mathrm{~mm}$, and are present in area of valve seats, and in area of injector seat under load of pressure in the cylinder. Region of the deformations near valve seats, from inlet collector side, is bigger than the one near valve seats from side of exhaust channels. Moreover, deformations area is bigger for inlet valve seat, located closer to frontal wall of the cylinder head model, and the inlet channel alone from the same side.

The highest deformations in direction of „y” axis, in opposite direction to its sense, are seen in area behind the second cylinder, towards the third cylinder, and they do not exceed value of $0.002 \mathrm{~mm}$.

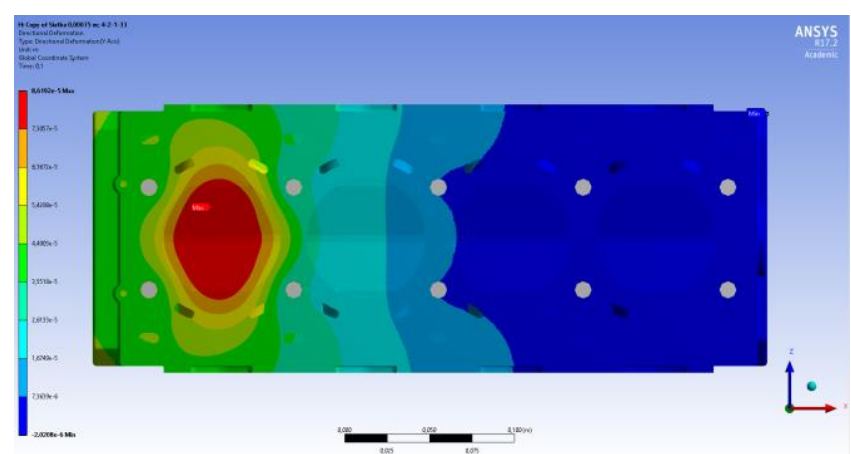

Fig. 18. Distribution of the deformations in direction of ,y” axis as results of simulation of the first cylinder loading - bottom view

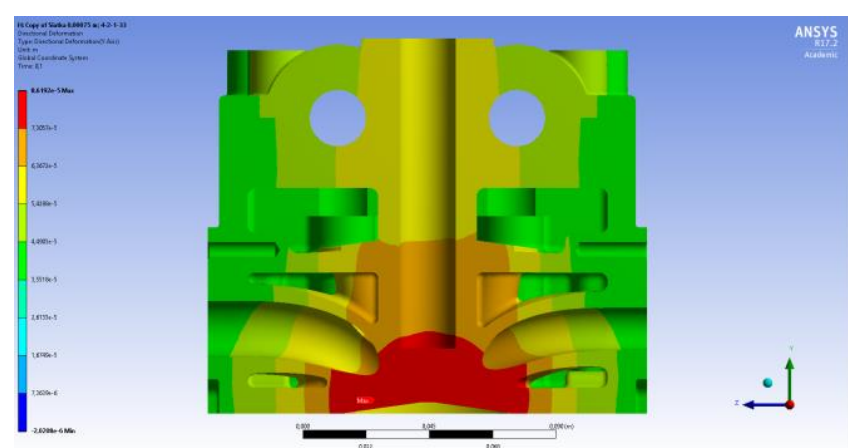

Fig. 19. Distribution of the deformations in direction of ,y" axis as results of simulation of the first cylinder loading - cross-section of the first cylinder

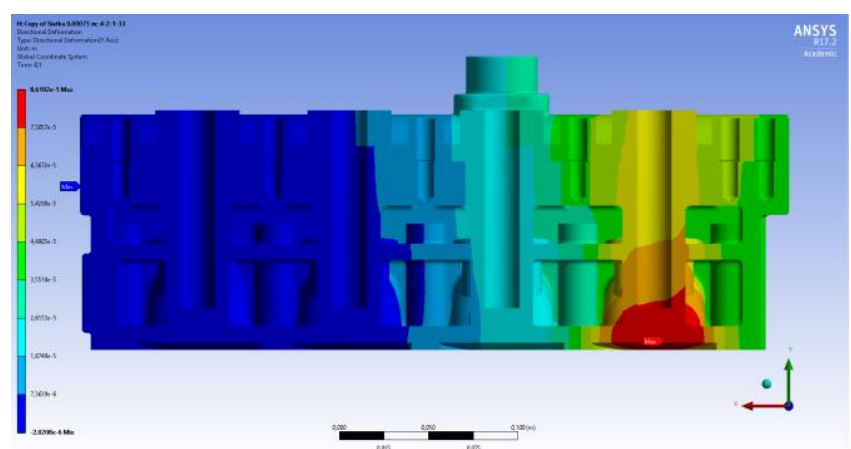

Fig. 20. Distribution of the deformations in direction of ,y” axis as results of simulation of the first cylinder loading - longitudinal view

d) Directional deformations concurrent with ,z" axis (Fig. 21):

The highest deformations in direction of ,z" axis, in direction of its sense, do not exceed value of $0.009 \mathrm{~mm}$ and occur at external part of inlet channel wall of loaded cylinder.

In turn, the highest deformations in direction of ,z" axis, opposite to its sense, do not exceed value of $0.009 \mathrm{~mm}$ and are present on external part of exhaust channel wall of loaded cylinder.

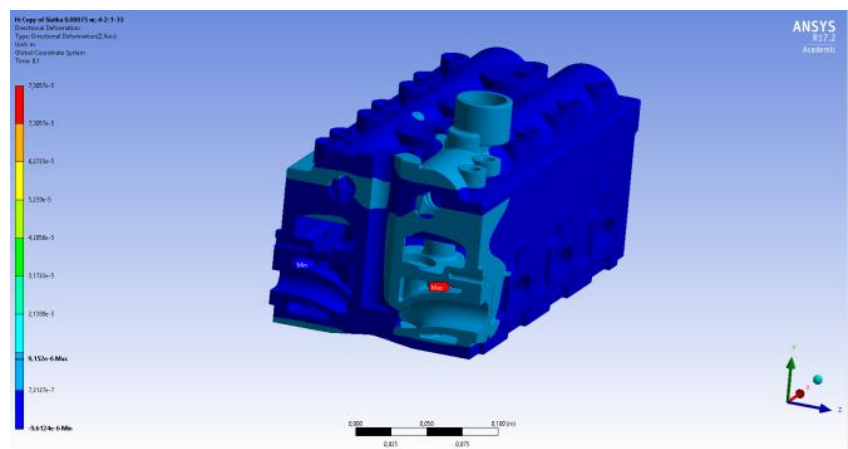

Fig. 21. Distribution of deformations in direction of ,z” axis as result of simulation of the first cylinder loading - general view

\subsection{Simulation results of the second cylinder loading}

a) Total deformations (Figs 22-25):

The highest deformations, included within interval of $0.079-0.082 \mathrm{~mm}$ are present in area of inlet valve seats of loaded cylinder. Also, high deformations can be seen in area of injector seat and exhaust valve seats of the cylinder under pressure load. 
The lowest deformations are present in area behind the third cylinder, in direction of the fourth cylinder, and also on frontal plate of the cylinder head, are included within range of $0.000-0.010 \mathrm{~mm}$.

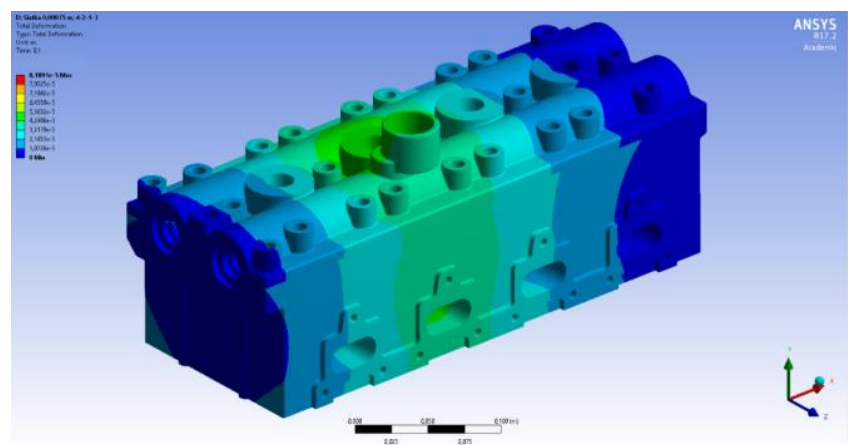

Fig. 22. Distribution of total deformations as result of simulation of second cylinder loading - general view

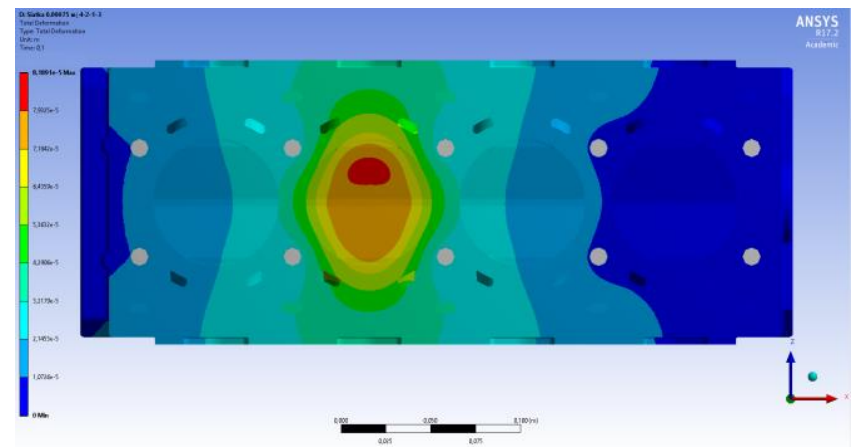

Fig. 23. Distribution of total deformations as result of simulation of second cylinder loading - bottom view

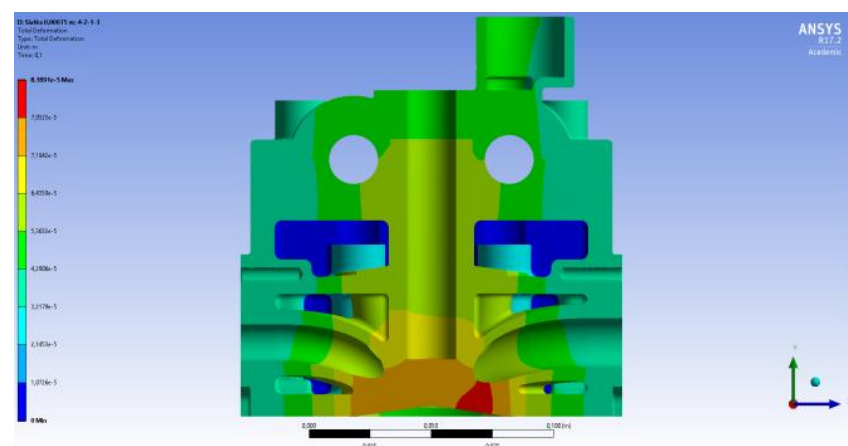

Fig. 24. Distribution of total deformations as result of simulation of second cylinder loading - cross-section of the second cylinder

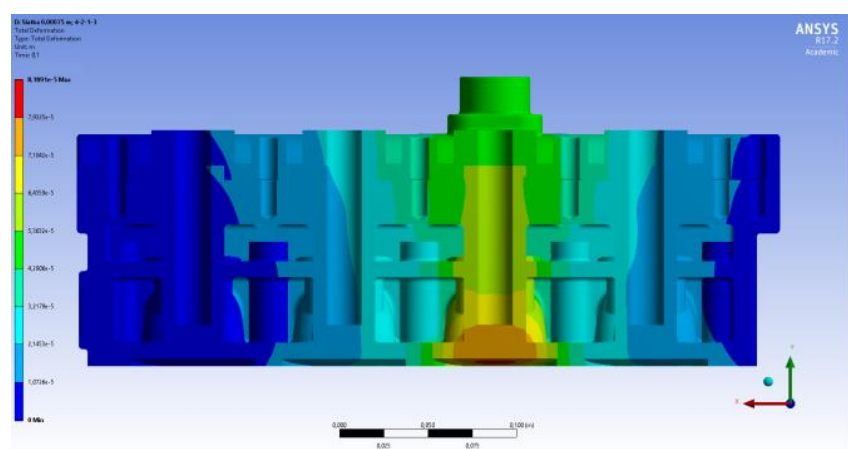

Fig. 25. Distribution of total deformations as result of simulation of the second cylinder loading - longitudinal section

\subsection{Results of simulation of the third cylinder loading}

a) Total deformations (Figs 26-29):

The highest deformations, contained within limits of $0.079-0.082 \mathrm{~mm}$ are present in area of inlet valve seats of loaded cylinder. Also high deformations can be observed in vicinity of injector seat and valve seats of exhaust channel of the cylinder under pressure load.

The lowest deformations appear in area behind the second cylinder, looking towards the first cylinder, and also in rear plate of the cylinder head, and are include with limits of $0.000-0.010 \mathrm{~mm}$

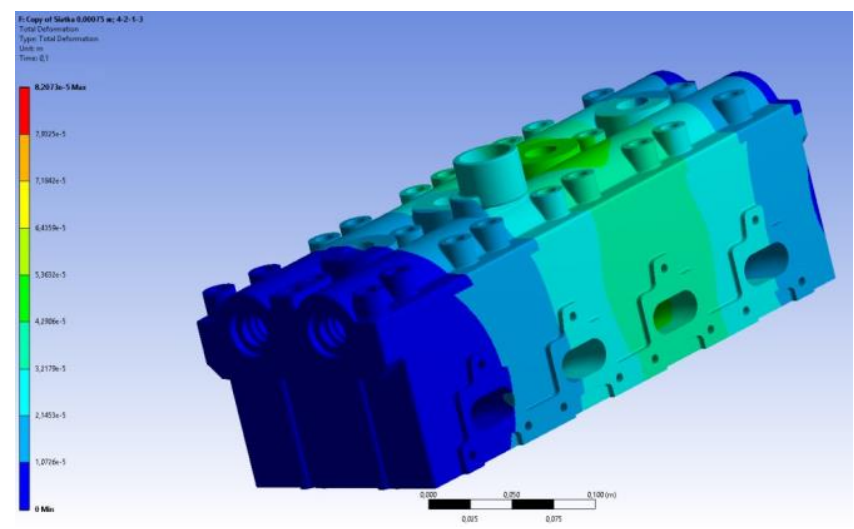

Fig. 26. Distribution of total deformations as result of simulation of the third cylinder loading - general view

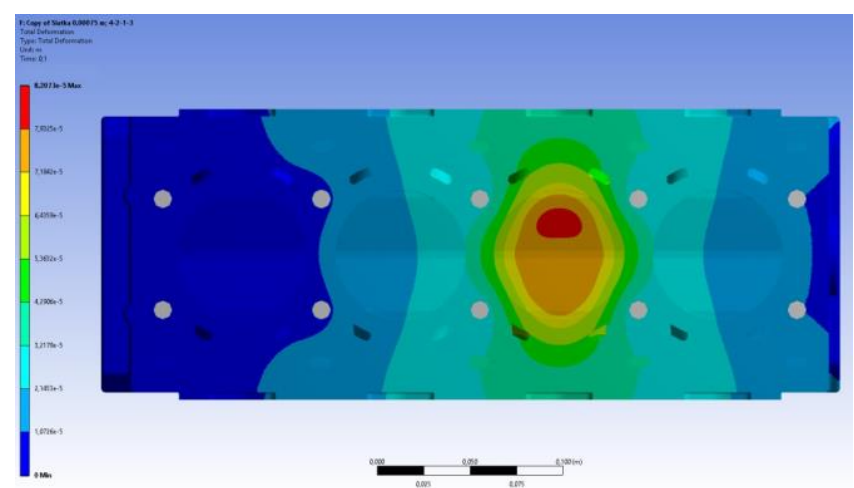

Fig. 27. Distribution of total deformations as result of simulation of third cylinder loading - bottom view

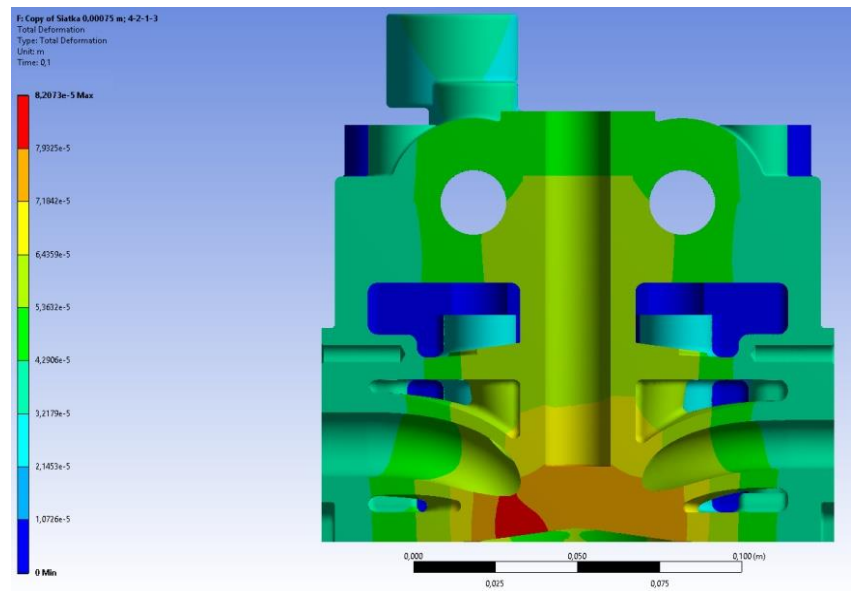

Fig. 28. Distribution of total deformations as result of simulation of the third cylinder loading - cross-section of the third cylinder 


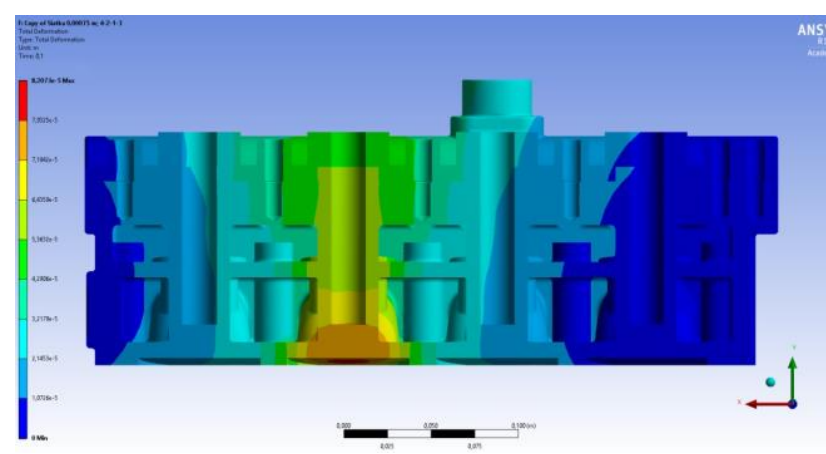

Fig. 29. Distribution of total deformations as result of simulation of the third cylinder loading - longitudinal section

\subsection{Simulation results of the fourth cylinder loading}

a) Total deformations(Figs 30-33) :

The highest deformations, included within limits of 0.079-0.086 mm occur in area of valve seats of inlet channel of loaded cylinder, in vicinity of the rear plate. Additionally, high deformations can be seen near seat of the injector and exhaust valve seats of the cylinder under pressure load.

The lowest deformations are present in area behind the third cylinder, looking towards direction of the second cylinder, and also in rear plate of the cylinder head, and are included within range of $0.000-0.012 \mathrm{~mm}$.

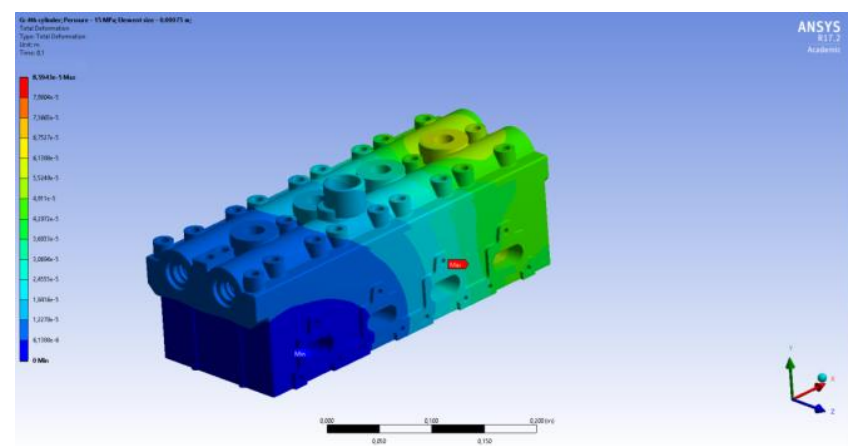

Fig. 30. Distribution of total deformations as result of simulation of the fourth cylinder loading - general view

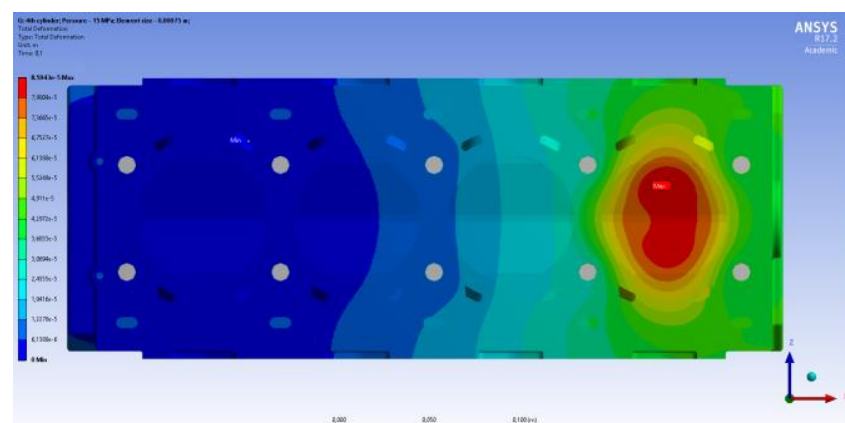

Fig. 31. Distribution of total deformations as result of simulation of the fourth cylinder loading - bottom view

\section{Conclusions}

- The highest total deformations are present during simulation of loading of the first and the fourth cylinder, and amount to $0.086 \mathrm{~mm}$;

- The lowest total deformations occur during simulation of loading of the second and the third cylinder, and amount to $0.082 \mathrm{~mm}$;

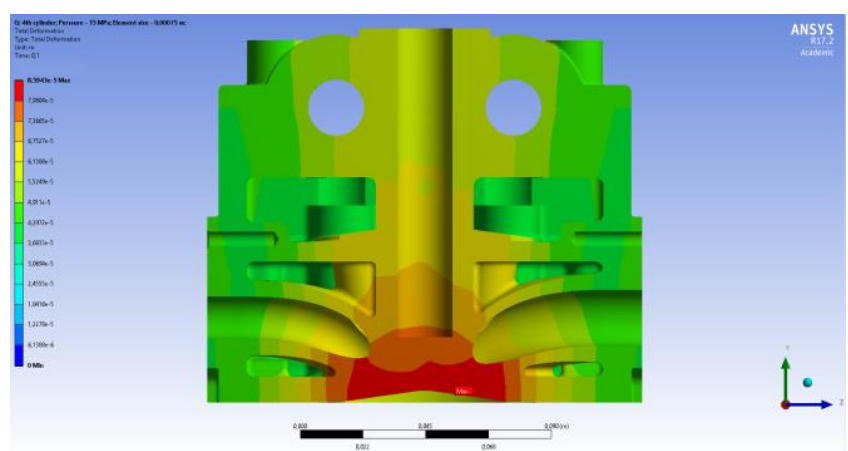

Fig. 32. Distribution of total deformations as result of simulation of the fourth cylinder loading - cross-section of the fourth cylinder

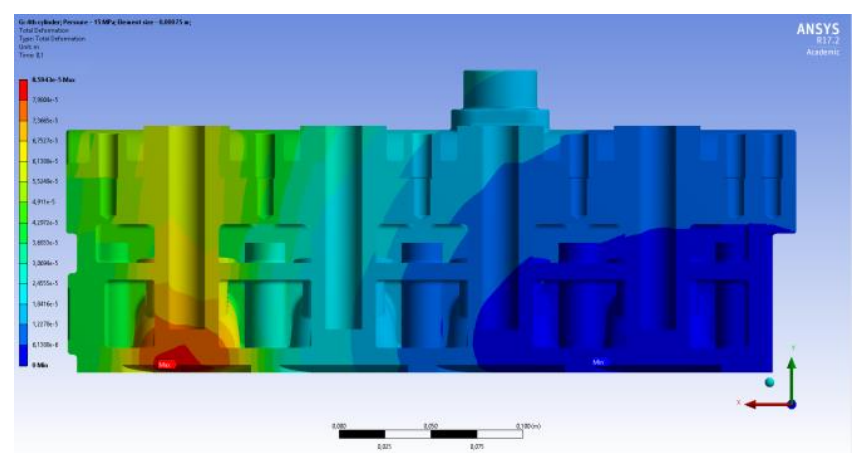

Fig. 33. Distribution of total deformations as result of simulation of the fourth cylinder loading - longitudinal section

- The highest directional deformations in direction of ,x” axis occur during simulation of loading of the first cylinder, and amount to $0.026 \mathrm{~mm}$;

- The lowest directional deformations in direction of „x" axis occur during simulation of loading of the second cylinder, and amount to $0.014 \mathrm{~mm}$;

- The highest directional deformations in direction of „y” axis occur during simulation of loading of the first and the fourth cylinder, and amount to $0.086 \mathrm{~mm}$;

- The lowest directional deformations in direction of "y" axis occur during simulation of loading of the second and the third cylinder, and amount to $0.082 \mathrm{~mm}$;

- The highest directional deformations in direction ,z” axis occur during simulation of loading of the second cylinder, and amount to $0.015 \mathrm{~mm}$;

- The lowest directional deformations in direction of , $\mathrm{z}$ axis occur during simulation of loading of the first cylinder, and amount to $0.009 \mathrm{~mm}$;

- Deformations in direction of the „y" axis have the biggest effect on the total deformations;

- The highest deformations in direction of ,y” axis are seen in case of the $1^{\text {st }}$ and the $4^{\text {th }}$ cylinder of the cylinder head;

- In course of design work of a cylinder heads it is necessary to perform careful analysis of already existing design solutions, to make layout of individual components for which the cylinder head serves as a kind of "jointer", and to have in mind feasibility of manufacturing of real component;

- Size of finite elements constituting mesh of discrete model is of very high importance for approximation of simulation results to result from real tests of loaded 
components. Smaller finite elements of the mesh enable obtainment of more accurate and burdened with lower error results;

- Processor capacity of a computer system performing calculations based on the Finite Elemente Methods is very important, because it allows for calculation of more complex cases;

- Lack of sufficient calculation capacity of computer system accomplishing numerical simulations of the cylinder head model has resulted in lacking possibility of generation of the mesh with size of finite element smaller than $0.75 \mathrm{~mm}$, and lacking possibility of simul- taneous performing of the simulations according to adopted assumptions;

- Authors of this study has in mind, that values of the deformations obtained in result of performed simulation of the cylinder head loading may differ from the real ones, and can exceed acceptable maximal deformations;

- Both the CAD and FEM programs are very useful tools in design engineer work, facilitating and accelerating its work with simultaneous reduction of costs connected with production of many constructions, among others.

\section{Bibliography}

[1] GRĄDZKI, R. Wprowadzenie do metody elementów skończonych, Wydawnictwo Politechniki Łódzkiej. Łódź 2002.

[2] JĘDRZEJOWSKI, J. Obliczenia tłokowego silnika spalinowego. WNT. Warszawa 1984.

[3] MATZKE, W. Projektowanie głowic silników trakcyjnych. WKE. Warszawa 1979.

[4] NUNNEY, M.J. Light and Heavy Vehicle Technology. Elsevier Ltd. 2007.
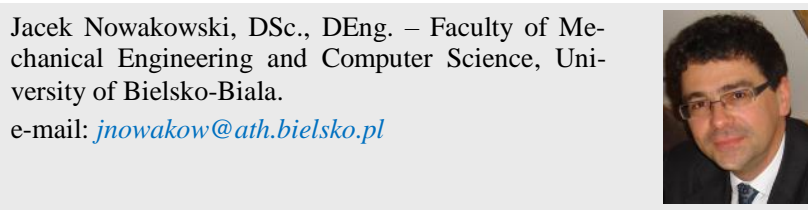

Szymon Cypcer, MEng. - Faculty of Mechanical Engineering and Computer Science, University of Bielsko-Biala

e-mail: szymoncypcer@gmail.com
[5] RAKOWSKI, G., KACPRZYK, Z. Metoda Elementów Skończonych w mechanice konstrukcji. Oficyna Wydawnicza Politechniki Warszawskiej. Warszawa 2005.

[6] STONE, R. Introduction to Internal Combustion Engines, SAE Inc., 1999.

[7] WAJAND, J.A., WAJAND, J.T. Tłokowe silniki spalinowe średnio- i wysokoobrotowe. WKE. Warszawa 2005.

Krzysztof Sikora, DEng. - Faculty of Mechanical Engineering and Computer Science, University of Bielsko-Biala.

e-mail: ksikora@ath.bielsko.pl 